\title{
First FDA-approved beta-amyloid diagnostic hits the market
}

The first beta-amyloid imaging agent for cases of suspected Alzheimer's disease approved by the US Food and Drug Administration (FDA) is now commercially available. On June 1, Eli Lilly of Indianapolis, and its Avid Radiopharmaceuticals subsidiary announced that Amyvid (florbetapir), a flourine-18 radiolabeled small-molecule tracer, was available from 16 radiopharmacies around the US. Radiologists in most major population centers can now perform brain positron emission tomography (PET) scans using the Amyvid tracer. But uncertainty over Medicare reimbursement and restrictive labeling imposed by the FDA, which approved Amyvid on April 6, will limit Amyvid's clinical use.

Amyvid won approval after a phase 3 trial in which trained PET readers, using Amyvid, estimated beta-amyloid burden in the brains of 29 dying patients, which was later compared during autopsy with beta-amyloid aggregates measured by neuropathologists in the same brains. Amyvid-PET achieved 93\% sensitivity and 100\% specificity, with Amyvid-PET diagnosis correlating closely with pathology results for the presence or absence of Alzheimer's in all but one patient in this trial. (J. Am Med. Assoc. 305, 275-283, 2011). Even so, because the trial population differed from that likely to use Amyvid, and an earlier trial showed inconsistent image interpretation, an FDA advisory committee, in January 2011, voted 13-3 against approval. Future approval was contingent on implementation by Avid of a training program showing consistency and accuracy in the intended patient population.

Table 1 PET tracers for Alzheimer's

\begin{tabular}{lll}
\hline Company & Tracer & Stage \\
\hline $\begin{array}{l}\text { Avid } \\
\begin{array}{l}\text { Radiopharmaceuticals/ } \\
\text { Eli Lilly }\end{array}\end{array}$ & Amyvid (florbetapir; 18F-AV-45) & $\begin{array}{l}\text { FDA approval } \\
\text { April 6 }\end{array}$ \\
\hline Piramal Healthcare & Florbetaben (BAY 94-9172) & Phase 3 \\
\hline GE Healthcare & Flutemetamol (GE-067) & Phase 3 \\
\hline $\begin{array}{l}\text { Navidea } \\
\text { BioPharmaceuticals }\end{array}$ & 18F-AZD4694 & Phase 2 \\
\end{tabular}

Such a program is now in place. But Amyvid's labeling emphasizes that a positive Amyvid scan does not establish a diagnosis of Alzheimer's disease, and that Amyvid-PET has not been shown to predict the development of dementia. (Betaamyloid plaques are often present in aged individuals with normal cognition.) Only negative Amyvid PET scans thus are likely to be useful, as a way to rule out Alzheimer's in patients with other cognitive disorders lacking amyloid pathology.

Given these caveats, several committees are drawing up guidelines for using Amyvid in the clinic, including a joint committee from the Society for Nuclear Medicine and the Alzheimer's Association. A representative from the Center for Medicare and Medicaid
Services (CMS) sits on the committee, but for now, Amyvid is currently ineligible for coverage by Medicare. That is because a 2000 CMS policy excludes future uses of PET, including FDA-approved radiopharmaceuticals, from coverage. Lilly, industry trade associations and medical professional societies have been working with CMS "to
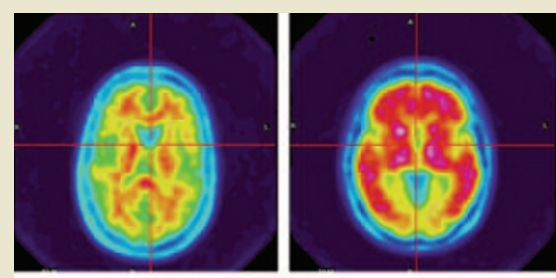

define a new path forward for PET imaging," says Lilly spokesperson Kelly McGrath in an e-mail. Medicare reimbursement is crucial.

"If nobody's going to pay for this service, even though technology is available, it's a little challenging to implement," says Satoshi Minoshima, director of the neuroimaging and biotech laboratory at the University of Washington in Seattle.

Despite these pending issues, Amyvid approval is a milestone that sets an important precedent, says Minoshima. Three other companies have beta-amyloid tracers in advanced clinical development, including two-GE Healthcare in Chalfont St. Giles, UK, and Piramal Healthcare in Mumbai, India-that have completed phase 3 trials (Table 1 ). One possible differentiator is specificity for brain beta-amyloid. PET tracers must be somewhat lipophilic to cross the blood-brain barrier, but this causes binding to white matter, which has a large lipid component. Navidea BioPharmaceuticals in Dublin, Ohio, claims its tracer (in-licensed from London-based AstraZeneca) has "negligible" white matter uptake, based on experiments in human brain sections and in mice. If so, this tracer, now in phase 2 , could produce clearer and more accurate PET images.

But even perfect beta-amyloid imaging will never diagnose Alzheimer's by itself. GE Healthcare is collaborating with Clino in Sendai, Japan, to discover and develop tracers for tau proteins, which also accumulate in Alzheimer brains, and Siemens in Munich has already reported such compounds at meetings. "Amyloid is just one part of the story," writes Jonathan Allis, PET general manager for GE Healthcare medical diagnostics, in an e-mail. "Tau and other non-PET, even nonimaging approaches are required to detect the disease. We are actively looking at other detection methods, from blood tests to improved MRI scanning techniques."

Ken Garber Ann Arbor, Michigan

\section{IN their words}

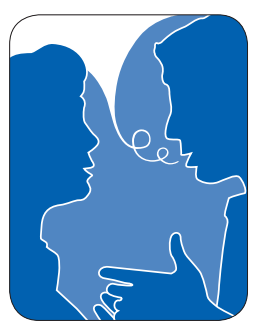

meeting in Lund, Sweden. (BioCentury, 9 May 2012)

"This allows us to focus on the important question of whether there are real barriers to drug innovation in the US. But it's clear from this study that the speed at which the FDA reviews drug applications is not one of them." Kathleen Stratton of the Pew Charitable Trusts. (The Washington Times, 16 May 2012)

\author{
"I understand politically that it's easier not to \\ approve than to approve." Kakha Bendukidze, \\ Soviet government minister and largest \\ shareholder of Maynard, Massachusetts-based \\ AquaBounty Technologies. AquaBounty awaits \\ word from the FDA that their genetically \\ engineered salmon can be sold. The agency \\ deemed it safe 20 months ago. \\ (New York Times, 21 May 2012)
}

